\title{
Níveis de Concentrado em Dietas de Novilhos Mestiços F1 Simental x Nelore. 2. Balanço Nitrogenado, Eficiência Microbiana e Parâmetros Ruminais ${ }^{1}$
}

\author{
Gilson Camargo Tibo ${ }^{2}$, Sebastião de Campos Valadares Filho ${ }^{3}$, José Fernando Coelho da Silva ${ }^{3}$ \\ Rilene Ferreira Diniz Valadares ${ }^{3}$, Maria Ignez Leão ${ }^{3}$, Paulo Roberto Cecon ${ }^{3}$, Ricardo Linhares Sampaio ${ }^{4}$
}

RESUMO - Foram avaliados os efeitos dos níveis de concentrado nas rações sobre a eficiência de síntese microbiana, o balanço de compostos nitrogenados, a concentração de amôniae opH do fluidoruminal, a taxa de passagem da digesta ruminal e as perdas endógenas de compostos nitrogenados (N). Foram utilizados cinco novilhos $\mathrm{F}_{1}$ Simental x Nelore, não-castrados, fistulados no rúmen, abomaso e íleo, alimentados à vontade com dietas que continham 25,0; 37,5; 50,0; 62,5; e 75,0\% de concentrado e distribuídos em delineamento quadrado latino 5x 5. As concentrações de amônia e o pH ruminal foram determinados em amostras de fluido ruminal coletadas imediatamente antes do fornecimento das rações e 2; 4; 6; e 8 horas após. A taxa depassagem foi determinada pelomodelounicompartimental, utilizando-se oóxidocrômicocomoindicador. A eficiência de síntese microbiana, expressa em relação à matéria orgânica degradada no rúmen (MODR), aos carboidratos totais degradados no rúmen (CHODR) e ao NDT, foi influenciada quadraticamente pelos níveis de concentrado na dieta, estimando-se valores máximos de 41,22 gNmic/kg MODR, 39,89 gNmic/kg CHODR e 17,33g PBmic/100 g NDT, estimados para 52,16; 60,44; e 56,63\% de concentrado na dieta, respectivamente. Quando expressa em MSmic/kg CHODR, a eficiência aumentou linearmente com o nível de concentrado. Foram estimados valores de $5,15 \mathrm{~g} \mathrm{~N} / \mathrm{kg}$ MS ingerida para o nitrogênio metabólico fecal e $422 \mathrm{mg} \mathrm{N} / \mathrm{kg}^{0,75}$ para as perdas endógenas totais. As concentrações máximas de amônia para todos os tratamentos ocorreram a 3,6 horas após o fornecimento da ração. As taxas de passagem de 0,$052 ; 0,052 ; 0,055 ; 0,055 ;$ e $0,042 . \mathrm{h}^{-1}$ foram verificadas para os tratamentos com 25,0; 37,5; 50,0; 62,$5 ;$ e 75,0\% de concentrado, respectivamente. A máxima eficiência microbiana foi obtida entre 52 e $60 \%$ de concentrado.

Palavras-chave: amônia ruminal, concentrado, eficiência microbiana, pH ruminal, taxa de passagem

\section{Concentrate Levels in the Crossbred F1 Simental x Nellore Bulls Diets. 2. Nitrogenous Balance, Microbial Efficiency and Ruminal Parameters}

\begin{abstract}
The effects of dietary concentrate levels were evaluated on the microbial synthesis efficiency, the nitrogenous compounds balance, the ammonia concentrations and the ruminal fluid $\mathrm{pH}$, the ruminal digesta passage rate and the endogenous losses of nitrogen compounds (N). Five $F_{1}$ Simental $x$ Nellore bulls fistulated in the rumen, abomasum and ileum, full fed diets with 25.0;37.5;50.0;62.5; and 75.0\% of concentrate and allotted to $5 \times 5$ Latin square, were used. The ammonia concentrations and the ruminal $\mathrm{pH}$ were determined in ruminal fluid samples immediately collected before and 2; 4; 6; and 8 hours after feeding. The unicompartimental model, using chromic oxide as indicator, determined the passage rate. The microbial synthesis efficiency, express in relation to the organic matter degraded in the rumen(OMDR), to the total carbohydrates degraded in the rumen (CHODR) and to TDN, was influenced in quadratic way by the concentrate levels in the diet, estimating maximum values of 41.22 gNmic/kg OMDR, $39.89 \mathrm{gNmic} / \mathrm{kg}$ CHODR and 17.33g CPmic/100 g NDT, estimated for 52.16, 60.44, and 56.63\% of concentrate in the diet, respectively. When express in DMmic/kg CHODR, the efficiency linearly increased as the concentrate level increased. Values of $5.15 \mathrm{~g} \mathrm{~N} / \mathrm{kg}$ ingested $\mathrm{DM}$ for the fecal metabolic nitrogen and $422 \mathrm{mg} \mathrm{N} / \mathrm{kg}^{0,75}$ for the total endogenous losses were estimated. The maximum ammonia concentrations for all treatments were observed at 3,6 hours after feeding. The passage rates of $.052, .052, .055, .055$, and $.042 . \mathrm{h}^{-1}$ were obtained for all treatments with $25.0,37.5,50.0,62.5$, and $75.0 \%$ of concentrate, respectively. The maximum microbial efficiency ranged from 52 to $60 \%$ of concentrate.
\end{abstract}

Key Words: ruminal ammonia, concentrate, microbial efficiency, ruminal $\mathrm{pH}$, passage rate

\section{Introdução}

Em virtude de a proteína ser um dos ingredientes mais caros da dieta, a economia da produção animal é altamente dependente da eficiência de sua utilização. Por esse motivo, nos últimos anos, tem havido considerável interesse na redução das perdas de compostos nitrogenados (N) pelos ruminantes (RUSSELL,1992).

Considerando o papel central da fermentação microbiana na digestão dos ruminantes, torna-se importante a avaliação do $\mathrm{N}$ disponível para a absorção pelo animal. Os compostos nitrogenados nãoamoniacais (NNA) no abomaso têm sido utilizados

\footnotetext{
${ }^{1}$ Parte da Tese de Mestrado apresentada pelo primeiro autor à UFV

2 Mestre em Zootecnia.

3 Professor da UFV.

${ }^{4}$ Bolsista de Iniciação Científica.
} 
para avaliar o $\mathrm{N}$ que chega ao ID e incluem, principalmente, $\mathrm{N}$ dietético não-degradado e $\mathrm{N}$ de origem microbiana. Os NNA totais do abomaso contêm ainda outra fração, a proteína endógena, constituída principalmente de enzimas, muco e células epiteliais (NATIONAL RESEARCH COUNCIL - NRC, 1985, citado por VALADARES et al., 1997a).

Segundo NOLAN (1993), a composição das células microbianas é relativamente constante, exceto pelo conteúdo de polissacarídeos, que é mais variável. Entretanto, CLARK et al. (1992) verificaram variações nos dados de literatura sobre a composição das bactérias, destacando valores médios de 77,5\% para matéria orgânica (MO), 7,71\% para nitrogênio (N), 7,28\% para RNA-purinas e $13,7 \%$ para a relação N-RNA:N-purina. Da mesma forma, VALADARES FILHO (1995) relatou valores médios obtidos de 10 experimentos de 84,$6 ; 7,1 ; 8,6$; e $17,6 \%$, respectivamente, para MO, N, RNA-purinas e relação N-RNA:N-total.

A produção diária de proteína microbiana pode ser obtida como o produto da eficiência microbiana, que usualmente é definida por $\mathrm{g}$ de $\mathrm{N}$ microbiano sintetizado por $\mathrm{kg}$ de $\mathrm{MO}$ fermentada no rúmen, e o total de MO $(\mathrm{kg})$ fermentada no rúmen por dia (HOOVER e STOKES, 1991).

O NRC (1996) expressou a eficiência de síntese microbiana como produção de proteína bruta microbiana (PBmic), em função dos nutrientes digestíveis totais (NDT) consumidos, e admitiu o valor médio de $13 \mathrm{~g}$ PBmic/100 g NDT como boa estimativa. O CNCPS expressou a eficiência microbiana em gramas de matéria seca (MS) microbiana (gMSbac) por grama de carboidratos totais degradados no rúmen (CHODR), por serem estes as fontes primárias de energia para o crescimento microbiano (RUSSELL et al., 1992). O AGRICULTURAL AND FOOD RESEARCH COUNCIL - AFRC (1993), entretanto, expressou essa eficiência em gramas de PB microbiana por MJ de energia metabolizável fermentada no rúmen.

O crescimento microbiano no rúmen é influenciado pela interação de fatores químicos, fisiológicos e nutricionais (HOOVER e STOKES, 1991). A disponibilidade energética é apontada como fator limitante para o crescimento microbiano, podendo a manipulação da dieta, por meio da alteração nas proporções de volumoso e concentrado, aumentar a quantidade de MO fermentada e, conseqüentemente, a síntese protéica (CLARK et al., 1992). A disponibilidade de energia para o crescimento microbiano depende da composição da dieta e da extensão de sua fermentação ruminal, que é, em primeiro momento, dependente da quantidade de carboidratos rapidamente hidrolisados - como açúcares, amido e pectina - e, posteriormente, da quantidade e composição dos componentes da parede celular (HOOVER e STOKES, 1991).

Redução na passagem de proteína microbiana para o ID, em dietas com mais de $70 \%$ de concentrado, pode ocorrer em virtude da alta taxa de degradação de CNE, resultando em fermentação nãoacoplada. Diminuição na passagem de proteína microbiana para o ID, observada quando as dietas têm elevados teores de volumosos, pode ser atribuída à deficiência de energia disponível na forma de CNE e ao aumento da reciclagem de compostos nitrogenados pelos microrganismos do rúmen (CLARK et al., 1992).

ZINN e OWENS (1983), estudando o efeito do nível de consumo sobre o fluxo de $\mathrm{N}$ no trato gastrintestinal (TGI) de novilhos recebendo dieta com $80 \%$ de concentrado, verificaram que a eficiência de síntese microbiana aumentou de 18,7 para 24,7 gNmic/kg MODR, quando o nível de consumo passou de 1,2 para 1,8\% do PV, em razão do aumento na taxa de diluição ruminal.

Em muitos casos, a taxa de produção de amônia no rúmen excede a taxa de utilização da mesma pelos microrganismos, ocasionando maior absorção de $\mathrm{NH}_{3}$ e, com isso, maior custo energético para o animal, devido à síntese de uréia para a sua excreção (RUSSELL et al., 1992).

A concentração de nitrogênio amoniacal $\left(\mathrm{N}-\mathrm{NH}_{3}\right)$ no rúmen é, portanto, indispensável para o crescimento bacteriano, desde que associada a fontes de energia, e está diretamente relacionada com a solubilidade da proteína dietética e a retenção de $\mathrm{N}$ pelo animal (COELHO DA SILVA e LEÃO, 1979). Segundo STERN e HOOVER (1979), para variadas situações, cerca de 40 a $100 \%$ do nitrogênio microbiano poderia ser derivado do $\mathrm{N}$ amoniacal.

$\mathrm{O}$ pH e a taxa de passagem são fatores químicos e fisiológicos que influem no crescimento microbiano, sendo ambos influenciados pela dieta e por outros fatores correlacionados, como o nível de consumo, o manejo alimentar, a quantidade e a qualidade da forragem, além da proporção volumoso:concentrado da dieta. A diminuição do pH reduz a degradabilidade da proteína, celulose, hemicelulose e pectina, embora seus efeitos sejam menores sobre a digestão do amido. Redução do pH de 6,5 para 5,5 diminui a 
eficiência de síntese microbiana (HOOVER e STOKES, 1991). Caso ocorra redução moderada no pH ruminal, até aproximadamente 6,0 , a digestão da fibra decresce um pouco, mas o número de microrganismos fibrolíticos não é normalmente influenciado. Quando o pH atinge a faixa de 5,5 a 5,0, há diminuição no número de microrganismos fibrolíticos, bem como em suas taxas de crescimento, causando inibição na digestão da fibra (HOOVER, 1986).

Aumentos no consumo proporcionam maior escape de $\mathrm{N}$ microbiano e de $\mathrm{N}$ dietético para $\mathrm{o}$ duodeno, possivelmente, em virtude do aumento nas taxas de passagem (VAN SOEST, 1994).

O presente trabalho foi conduzido com o objetivo de avaliar o efeito de níveis de concentrado sobre a eficiência de síntese microbiana, o pH e as concentrações de amônia ruminal, a taxa de passagem e o balanço de compostos nitrogenados (BN) em novilhos mestiços $F_{1}$ Simental x Nelore. Avaliaram-se também as perdas endógenas de compostos nitrogenados.

\section{Material e Métodos}

O local do experimento, os animais, a composição da dieta, os sistemas de alimentação e manejo e o delineamento experimental utilizados foram descritos por TIBO et al. (2000).

Em cada período experimental, foram utilizados dez dias para adaptação dos animais à dieta; quatro dias para coletas de fezes, digestas de abomaso e íleo; um dia para coleta de urina; e dois dias para coleta de digesta ruminal para determinação da taxa de passagem, quando também, no segundo dia, se procedeu à coleta de líquido ruminal para determinação do $\mathrm{pH}$ e das concentrações de $\mathrm{N}^{-\mathrm{NH}_{3}}$. Na manhã do $18^{\circ}$ dia, efetuou-se a coleta de digesta ruminal para o isolamento de bactérias.

As amostras de urina, em cada período experimental, foram obtidas de coletas de 12 horas ( 8 às 20 h), sendo o volume encontrado multiplicado por dois para a obtenção do volume urinário diário. Utilizaram-se funis coletores fixados por alças elásticas amarradas ao dorso dos animais. Mangueiras de borracha, acopladas aos funis, conduziam a urina até recipientes plásticos contendo $100 \mathrm{~mL}$ de solução de $\mathrm{HCl}$ 1:1. Após a coleta, os recipientes contendo urina foram devidamente pesados, para determinação do volume total produzido, e homogeneizados. Em seguida, foram retiradas alíquotas de $100 \mathrm{~mL}$, aproximadamente, que foram devidamente identificadas e armazenadas a $-5^{\circ} \mathrm{C}$, para posterior quantificação de compostos nitrogenados.

As coletas de líquido ruminal, visando à determinação do $\mathrm{pH}$ e das concentrações de $\mathrm{N}-\mathrm{NH}_{3}$, foram realizadas imediatamente antes do fornecimento da dieta e 2; 4; 6; e 8 horas após. Foram coletados por meio da fístula ruminal, aproximadamente $50 \mathrm{~mL} \mathrm{de}$ líquido, procedendo-se à imediata determinação do $\mathrm{pH}$, em peagâmetro digital. Após a leitura do $\mathrm{pH}$, adicionou-se, a cada amostra, $1 \mathrm{~mL}$ de solução de $\mathrm{H}_{2} \mathrm{SO}_{4} 1: 1$, que foi armazenada a $-5^{\circ} \mathrm{C}$, para posterior determinação das concentrações de $\mathrm{N}-\mathrm{NH}_{3}$.

A quantificação dos compostos nitrogenados nãoamoniacais (NNA) nas digestas de abomaso e íleo foi obtida por diferença entre o nitrogênio total e o N$\mathrm{NH}_{3}$ determinado em amostras in natura dos líquidos de abomaso e íleo, obtidas após centrifugação do material a $1.500 \mathrm{rpm}$.

As concentrações de $\mathrm{N}-\mathrm{NH}_{3}$ nas amostras do líquido ruminal filtrado e nos fluidos de abomaso e íleo foram determinadas mediante destilação com hidróxido de potássio $2 \mathrm{~N}$, conforme técnica de Fenner (1965), adaptada por VIEIRA (1980).

Os compostos nitrogenados metabólicos fecais (NMF) foram estimados por regressão entre o $\mathrm{N}$ digestível (Y) e a ingestão de N (X), expressos em g de N/kg MS, representados pela intercepta da regressão. As perdas endógenas de $\mathrm{N}$, incluindo as fecais e urinárias, foram estimadas pela regressão entre o balanço de $\mathrm{N}(\mathrm{Y})$ e a ingestão de $\mathrm{N}(\mathrm{X})$, expressos em $\mathrm{g} / \mathrm{kg}^{0,75}$, também representadas pela intercepta.

As taxas de passagem foram determinadas por intermédio do modelo unicompartimental, tendo sido o óxido crômico utilizado em uma única dose de $20 \mathrm{~g}$, via fístula ruminal. As amostragens de conteúdo ruminal foram realizadas imediatamente antes do fornecimento do indicador e $3 ; 6 ; 9 ; 12 ; 24 ; 36$; e 48 horas após. As amostras, acondicionadas em sacos plásticos, foram armazenadas a $5^{\circ} \mathrm{C}$ para, posteriormente, serem descongeladas à temperatura ambiente, pré-secas em estufa ventilada a $65^{\circ} \mathrm{C}$ por 72 horas, moídas em moinho com peneira com malha de $1 \mathrm{~mm}$ e, finalmente, submetidas às análises para determinação da matéria seca definitiva e cromo, conforme técnica descrita por SILVA (1990).

Para o cálculo das taxas de passagem $(\mathrm{k})$, foi utilizado o modelo $Y=a . e^{-k t}$, em que "Y" é a concentração do indicador no tempo "t" e "a", a concentração inicial do indicador (CZERKAWSKI,1986).

No último dia de cada período experimental, foram obtidas amostras de digesta ruminal, de cada 
animal, para o isolamento de bactérias, conforme metodologia descrita por CECAVA et al. (1990). As bases purinas foram utilizadas como indicador microbiano para quantificação de microrganismos nas digestas ruminal e abomasal, cuja determinação seguiu a técnica descrita por USHIDA et al. (1985).

As análises estatísticas do $\mathrm{pH}$ ruminal e das concentrações de $\mathrm{N}-\mathrm{NH}_{3}$ foram realizadas no esquema de parcelas subdivididas, tendo nas parcelas os níveis de concentrado e nas subparcelas os tempos de amostragem, em delineamento inteiramente casualizado com 125 repetições.

As demais análises químicas e os procedimentos de análises estatísticas utilizados foram feitos conforme descrito por TIBO et al. (2000).

\section{Resultados e Discussão}

Na Tabela 1, são demonstrados os valores médios diários de consumo total de compostos nitrogenados $(\mathrm{N})$, fluxos de $\mathrm{N}$ totais, amoniacais $\left(\mathrm{N}-\mathrm{NH}_{3}\right)$ e nãoamoniacais (NNA) no abomaso e íleo, $\mathrm{N}$ bacteriano no abomaso, excreções fecais e urinárias de $\mathrm{N}$ e balanço de $\mathrm{N}$ (BN).

Os consumos médios de $\mathrm{N}$, expressos tanto em $\mathrm{g} /$ dia como em $\mathrm{g} / \mathrm{kg}^{0,75}$, elevaram-se linearmente $(\mathrm{P}<0,01)$ com o aumento nos níveis de concentrado das rações, como reflexo do crescimento do consumo de MS relatado por TIBO et al. (2000), assim como em razão das maiores concentrações de $\mathrm{PB}$ nas dietas com níveis mais elevados de concentrado.

Os aumentos nos níveis de consumo de $\mathrm{N}$ acarretaram maiores fluxos de $\mathrm{N}$ total $\mathrm{e} \mathrm{N}-\mathrm{NH}_{3}$ no abomaso, que apresentaram comportamento linear crescente $(\mathrm{P}<0,01)$, enquanto o fluxo de NNA apresentou comportamento quadrático $(\mathrm{P}<0,05)$, estimando-se o fluxo máximo de $128,53 \mathrm{~g} /$ dia com $72,0 \%$ de concentrado na dieta.

$\mathrm{O}$ fluxo de $\mathrm{N}$ bacteriano também apresentou comportamento quadrático $(\mathrm{P}<0,0611)$, em função dos níveis de concentrado, obtendo valor máximo estimado de $114,58 \mathrm{~g} \mathrm{~N}$, com nível de $69,3 \%$ de concentrado na dieta. Segundo o AGRICULTURAL RESEARCH COUNCIL - ARC (1984), dietas ricas em concentrado, em torno de $70 \%$ ou mais, podem resultar em menor síntese microbiana, decorrente de inadequado suprimento de proteína degradada no rúmen; alta produção de ácido lático, resultando em menor suprimento de ATP; e menor salivação e ruminação, ocasionando menor taxa de passagem de líquidos e, conseqüentemente, menor fluxo de $\mathrm{N}$ bacteriano. CLARK et al. (1992) afirmaram que aumentos nos consumos de MS estão relacionados a maiores fluxos de $\mathrm{N}$ bacteriano para o abomaso.

Os fluxos de $\mathrm{N}$ total, $\mathrm{N}_{-} \mathrm{NH}_{3}$ e NNA no íleo não foram influenciados $(\mathrm{P}>0,05)$ pelos níveis de concentrado da ração, mostrando valores médios de 37,88 ; 3,19; e 34,70 g/dia, respectivamente.

A excreção de $\mathrm{N}$ fecal, expressa tanto em $\mathrm{g} / \mathrm{dia}$ como em $\mathrm{g} / \mathrm{kg}^{0,75}$, apresentou valores máximos de $44,03 \mathrm{~g} / \mathrm{dia}$ e $0,64 \mathrm{~g} / \mathrm{kg}^{0,75}$, nos níveis estimados de concentrados de 64,1 e $75,0 \%$, respectivamente. DIAS (1999), trabalhando com novilhos mestiços F1 Limousin $\mathrm{x}$ Nelore, alimentados com rações contendo as mesmas proporções de concentrado que as do presente experimento, obteve $44,65 \mathrm{~g} /$ dia e $0,67 \mathrm{~g} / \mathrm{kg}^{0,75}$, respectivamente, estimados para 52,4 e 53,3\% de concentrado.

A excreção de $\mathrm{N}$ na urina, expressa em g/dia e $\mathrm{g} / \mathrm{kg}^{0,75}$, cresceu linearmente $(\mathrm{P}<0,05)$ com o aumento nos níveis de concentrado nas rações, possivelmente como conseqüência dos aumentos nos níveis da proteína dietética e do consumo de $\mathrm{N}$, segundo considerações de VAN SOEST (1994).

$O$ balanço de nitrogênio, independente do modo como foi expresso, aumentou linearmente $(\mathrm{P}<0,01)$ com os níveis de concentrado da dieta, demonstrando que o maior aporte de compostos $\mathrm{N}$ no abomaso resultou em maior retenção de $\mathrm{N}$ no organismo animal, concordando com os resultados obtidos por VALADARES et al. (1997b).

A regressão de $\mathrm{N}$ digestível (Y) e a ingestão de $\mathrm{N}(\mathrm{X})$, expressas em $\mathrm{g}$ de N/kg MS, foi $\hat{\mathrm{Y}}=-5,15309$ $+0,93945 X, r^{2}=0,97, P<0,01$. Com base nesta equação, os compostos nitrogenados metabólicos fecais (NMF) corresponderiam a 5,15 g de N/kg MS ingerida. Este valor é semelhante ao reportado por VALADARES et al. (1997a) e LADEIRA (1998), que foi de 5,98 e $5,17 \mathrm{~g}$ de N/kg MS ingerida, respectivamente.

As perdas endógenas de $\mathrm{N}$, incluindo fecais e urinárias, obtidas por regressão entre o balanço de $\mathrm{N}$ (Y) e a ingestão de $\mathrm{N}(\mathrm{X})$, expressos em $\mathrm{g} / \mathrm{kg}^{0,75}$, foram de $0,422 \mathrm{~g}$ de $\mathrm{N} / \mathrm{kg}^{0,75}$, representadas pela intercepta da regressão: $\hat{Y}=-0,42152+0,44738 X$, $\mathrm{r}^{2}=0,39, \mathrm{P}<0,01$.

Considerando o peso vivo médio de $327,7 \mathrm{~kg}$, para os animais do presente experimento, os requisitos de proteína metabolizável para mantença, segundo o NRC (1996), seriam de 3,8 g/ $\mathrm{kg}^{0,75}$ ou 292,68 g/dia e, de acordo com o AFRC (1993), 2,3 g/ $/ \mathrm{kg}^{0,75}$ ou 177,15 $\mathrm{g} /$ dia. A estimativa de $0,422 \mathrm{~g} \mathrm{de} \mathrm{N} / \mathrm{kg}^{0,75}$, obtida por regressão entre o balanço de $\mathrm{N}$ e a ingestão de $\mathrm{N}$, 
Rev. bras. zootec.

Tabela 1 - Médias e regressão dos compostos nitrogenados $(\mathrm{N})$ ingeridos, presentes no abomaso e íleo, excretados nas fezes e na urina, e balanço de compostos nitrogenados (BN), em relação aos níveis de concentrado nas rações

Table 1 - Means and regression of the ingested nitrogenous compounds, present in the abomasum and ileum, excreted in the feces and urine, and the nitrogenous compounds balance (NB) on the concentrate levels in the diets

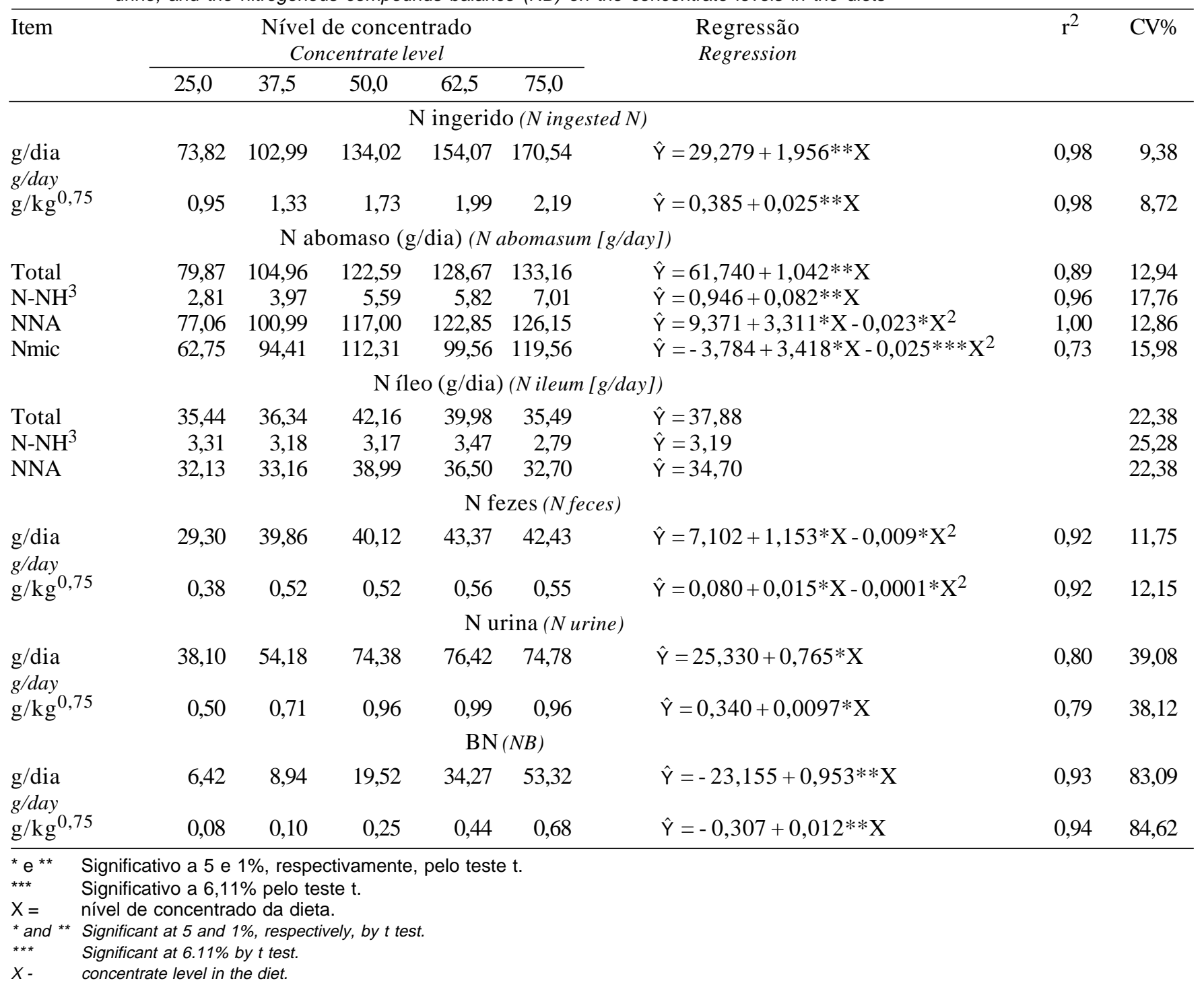

para as perdas endógenas no presente experimento, admitindo eficiência igual a 1 , corresponderia à proteína metabolizável, de $2,64 \mathrm{~g} / \mathrm{kg}^{0,75}$ ou $203,34 \mathrm{~g} /$ dia, mais próxima à recomendada pelo AFRC (1993).

A composição das bactérias ruminais demonstrada na Tabela 2 mostra que a média de $6,39 \%$ obtida para $\mathrm{N}$-total, entre os tratamentos, é próxima aos valores de 7,71 e 7,10\% de N-total, obtidos a partir de compilação de dados da literatura relatados por CLARK et al. (1992) e VALADARES FILHO (1995), respectivamente. Esses autores citaram valores médios de 13,7 e 17,8\% para a relação N-RNA:N-total, os quais são superiores à média de $5,68 \%$ obtida no presente trabalho. Os valores de 4,35 e 3,33\%, obtidos para a relação N-RNA:N-total nos tratamentos com 62,5 e $75,0 \%$ de concentrado, são bastante discrepantes da média e dos valores individuais obtidos nos demais tratamentos, o que pode ser atribuído a dificuldades no isolamento das bactérias em amostras de digesta obtidas de animais alimentados com altos níveis de concentrado (LADEIRA, 1998). Em virtude da variação de 8,34 a 3,33\% encontrada para a relação N-RNA:N-total nos diferentes tratamentos, decidiu-se usar a relação média obtida para os três primeiros tratamentos $(25,0 ; 37,5$; e $50,0 \%$ de concentrado), de $6,91 \%$, para calcular a produção microbiana em todos os tratamentos. Apesar disso, esta média está abaixo do valor médio sugerido por CHEN e GOMES (1992), que foi da ordem de 11,6\%.

$\mathrm{A}$ adição de concentrado à dieta dos animais 
proporcionou aumentos lineares $(\mathrm{P}<0,01)$ nas quantidades de MODR, CHODR e MSmic (Tabela 3). Estes resultados concordam com os obtidos por LADEIRA (1998) e DIAS (1999) com relação ao comportamento verificado para a MODR e CHODR. Para produção de MSmic, LADEIRA (1998) observou efeito quadrático com os níveis de concentrados da dieta, enquanto DIAS (1999) obteve valor médio de $635,27 \mathrm{~g} / \mathrm{dia}$.

A eficiência de síntese microbiana, expressa em gNmic/kg MODR, gNmic/kg CHODR e g PBmic/ $100 \mathrm{~g}$ NDT, foi influenciada quadraticamente $(\mathrm{P}<0,05$; $\mathrm{P}<0,0633$; e $\mathrm{P}<0,05$, respectivamente) pelos níveis de concentrado na dieta (Tabela 3). Os valores máximos para a eficiência microbiana foram $41,22 \mathrm{gNmic} / \mathrm{kg}$ MODR, 39,89 gNmic/kg CHODR e 17,33 gPBmic/

Tabela 2 - Valores médios de matéria seca (MS), matéria orgânica (MO), carboidratos totais $(\mathrm{CHO})$, extrato etéreo (EE), $\mathrm{N}$ do ácido ribonucléico (N-NRA) e relação $\mathrm{N}-\mathrm{RNA}: \mathrm{N}$-total das bactérias isoladas do rúmen

Table 2 - Average values of dry matter (DM), organic matter (OM), total carbohydrates, ether extract, ribonucleic acid $N(N-N R A)$ and $N-R N A: N$-total ratio of the isolated rumen bacteria

\begin{tabular}{lrrrrr}
\hline Item & \multicolumn{5}{c}{$\begin{array}{c}\text { Nível de concentrado } \\
\text { Concentrate level }\end{array}$} \\
\cline { 2 - 6 } & 25,0 & 37,5 & 50,0 & 62,5 & 75,0 \\
\hline MS & 96,91 & 96,42 & 95,06 & 92,11 & 91,34 \\
DM & & & & & \\
MO & 87,32 & 88,39 & 88,72 & 90,42 & 90,79 \\
OM & & & & & \\
CHO & 38,84 & 37,22 & 37,07 & 33,75 & 34,64 \\
EE & 5,24 & 7,00 & 10,33 & 13,24 & 16,75 \\
N-Total & 6,70 & 6,81 & 6,28 & 6,40 & 5,76 \\
N-RNA & 0,58 & 0,49 & 0,36 & 0,30 & 0,21 \\
N-RNA:N-Total & 8,34 & 6,94 & 5,45 & 4,35 & 3,33 \\
\hline
\end{tabular}

Tabela 3 - Médias e regressão da matéria orgânica degradada no rúmen (MODR), dos carboidratos totais degradados no rúmen (CHODR), da matéria seca microbiana (MSmic) presente no abomaso e da eficiência microbiana, expressa em g Nmic/kg MODR (1), g Nmic/kg CHODR (2), g MSmic/kg CHODR (3) e g PBmic/100 g NDT (4), em relação aos níveis de concentrado nas rações

Table 3 - Means and regression of organic matter degraded in the rumen (OMDR), total carbohydrates degraded in the rumen (CHODR), microbial dry matter (MDM) present in the abomasum and microbial efficiency, express in $\mathrm{g} \mathrm{Nmic/kg} \mathrm{OMDR} \mathrm{(1),} \mathrm{g} \mathrm{Nmic/kg,}$ CHODR (2), g DMmic/kg CHODR (3) and g CPmic/100 g NDT (4), on the concentrate levels in the diets

\begin{tabular}{|c|c|c|c|c|c|c|c|c|}
\hline \multirow[t]{2}{*}{ Item } & \multicolumn{4}{|c|}{$\begin{array}{l}\text { Nível de concentrado } \\
\text { Concentrate level }\end{array}$} & \multirow{2}{*}{\multicolumn{2}{|c|}{$\begin{array}{l}\text { Regressão } \\
\text { Regression }\end{array}$}} & \multirow[t]{2}{*}{$\mathrm{r}^{2}$} & \multirow[t]{2}{*}{$\mathrm{CV} \%$} \\
\hline & 25,0 & 37,5 & 50,0 & 62,5 & & & & \\
\hline $\begin{array}{l}\text { MODR }^{5} \\
O M D R\end{array}$ & 2,31 & 2,45 & 2,52 & 3,07 & 3,23 & $\hat{\mathrm{Y}}=1,737+0,019 * * \mathrm{X}$ & 0,91 & 14,56 \\
\hline $\mathrm{CHODR}^{5}$ & 2,46 & 2,75 & 2,63 & 3,09 & 3,04 & $\hat{Y}=2,194+0,012 * * X$ & 0,78 & 10,22 \\
\hline $\begin{array}{l}\mathrm{MSmic}^{6} \\
M D M\end{array}$ & 906,95 & 1335,84 & 1698,84 & 1432,83 & 1896,54 & $\hat{\mathrm{Y}}=623,732+16,609 * * \mathrm{X}$ & 0,1761 & 16,87 \\
\hline 1 & 27,22 & 39,32 & 46,14 & 33,32 & 38,02 & $\hat{Y}=-3,868+1,699 * * X-0,016 * X^{2}$ & 0,55 & 18,60 \\
\hline 2 & 25,71 & 35,49 & 43,16 & 32,97 & 40,43 & $\hat{Y}=2,268+1,245 * X-0,0103 * * * X^{2}$ & 0,59 & 18,50 \\
\hline 3 & 371,60 & 502,20 & 652,88 & 474,51 & 641,32 & $\hat{\mathrm{Y}}=323,793+4,094 * * \mathrm{X}$ & 0,46 & 19,04 \\
\hline 4 & 12,37 & 16,37 & 17,32 & 13,21 & 14,97 & $\hat{Y}=4,503+0,453 * X-0,004 * X^{2}$ & 0,40 & 15,08 \\
\hline
\end{tabular}

* $e^{* *}$ Significativo a 5 e $1 \%$, respectivamente, pelo teste $t$

$\star * * \quad$ Significativo a $6,33 \%$ pelo teste $t$.

$X=\quad$ Nível de concentrado da dieta.

$5 \quad \mathrm{~kg} / \mathrm{dia}$.

$6 \mathrm{~g} / \mathrm{dia}$

* and ** Significant at 5 and 1\%, respectively, by $t$ test.

*** Significant at $6.33 \%$ by $t$ test.

$X \quad$ Concentrate level in the diet.

$5 \quad \mathrm{~kg} / \mathrm{day}$.

6 g/day 
100 g NDT, estimados para 52,2; 60,4; e 56,6\% de concentrado na dieta, respectivamente. Quando expressa em MSmic/kg CHODR, a eficiência aumentou linearmente $(\mathrm{P}<0,01)$ com o nível de concentrado (Tabela 3).

A manipulação das proporções de volumosos e concentrados da dieta tem sido apontada como forma de maximizar a eficiência de síntese microbiana (CLARK et al., 1992).

SNIFFEN e ROBINSON (1987) afirmaram que o crescimento microbiano máximo é atingido com $70 \%$ de volumoso, devido às melhores condições de $\mathrm{pH}$, à taxa de renovação e às condições para a colonização; no entanto, os resultados do presente trabalho indicam proporções de 40 a $50 \%$.

No presente experimento, a eficiência microbiana expressa em PBmic/100g NDT variou de 12,37 a 17,32 e está de acordo com o NRC (1996), que, embora considere o valor fixo de $13 \mathrm{~g}$ PBmic/100g NDT, admite que pode haver variações, como aumentos na eficiência de síntese, com o incremento no consumo de NDT, devido a maiores taxas de passagem.

Na Figura 1, são demonstradas as estimativas do pH do líquido ruminal, em função dos tempos de coleta das amostras, para os cinco níveis de concentrado. Ocorreu interação significativa entre os tempos após a alimentação e os níveis de concentrado da dieta, porém os efeitos individuais não foram significativos. Pode-se observar que o efeito de tempo foi progressivamente maior, para reduzir os valores de $\mathrm{pH}$, com o aumento dos níveis de concentrado na dieta.

CECAVA et al. (1991) verificaram redução do $\mathrm{pH}$ ruminal de 6,10 para 5,86, quando forneceram níveis alto e baixo de fibra para novilhos, sendo este comportamento reflexo da substituição progressiva da FDN por CHO mais solúveis, cuja taxa de fermentação é mais rápida.

Os valores obtidos para o $\mathrm{pH}$ do líquido ruminal mostraram variações entre 7,04 e 5,51. Valores entre 6,59 e 5,44 foram encontrados por DIAS (1999).

Na Figura 2, são mostrados os valores estimados para as concentrações de amônia $\left(\mathrm{N}-\mathrm{NH}_{3}\right)$ no líquido ruminal, expressas em mg/100 mL, em função dos tempos de coleta para os cinco níveis de concentrado. As concentrações de $\mathrm{N}-\mathrm{NH}_{3}$ apresentaram aumentos lineares com a elevação nas proporções de concentrado da ração. Em razão de as dietas terem sido formuladas buscando-se a sincronização da degradação de carboidratos e proteínas, esperava-se que as concentrações de $\mathrm{N}-\mathrm{NH}_{3}$ não variassem com o aumento nos níveis de concentrados ou de energia, mas

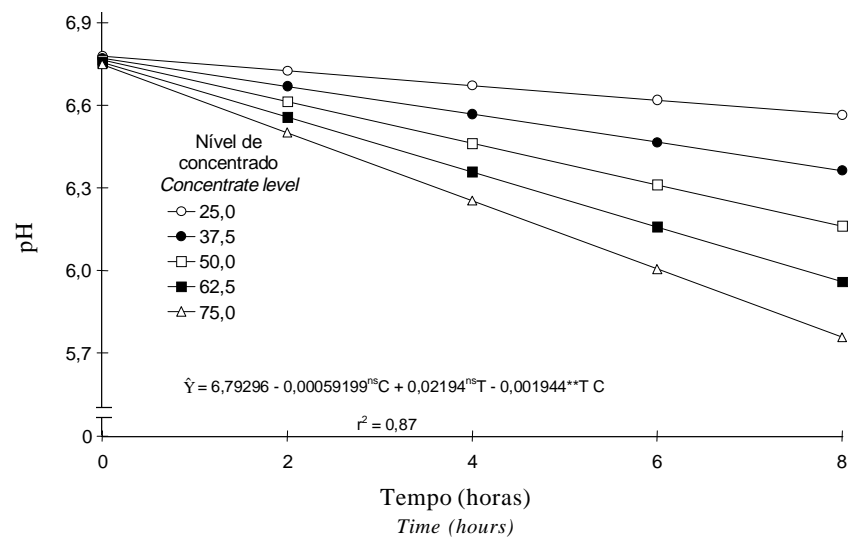

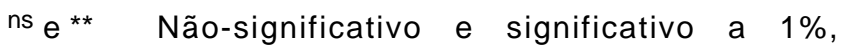
respectivamente, pelo teste t.

ns and ** Non significant and significant at 1\%, respectively, by $t$ test.

Figura 1- Estimativa do pH ruminal, em função dos tempos (T) de coleta, para cada nível de concentrado (C) na dieta.

Figure 1- Estimate of the ruminal $\mathrm{pH}$, in function of collection times $(T)$, for each concentrate level in the diet.

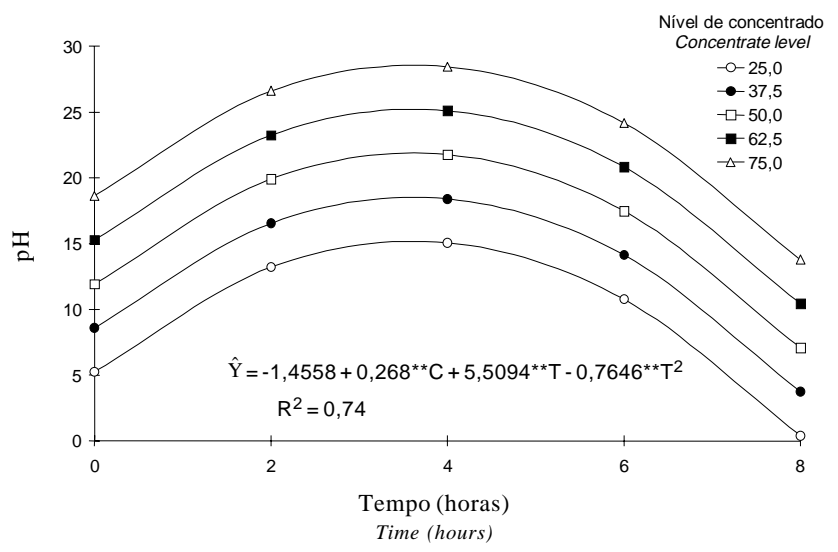

** Significativo a $1 \%$ de probabilidade pelo teste t. ** Significant at $1 \%$ respectively, by $t$ test.

Figura 2 - Estimativa das concentrações de amônia ruminal, em função dos tempos (T) de coleta, para cada nível de concentrado $(C)$ na dieta.

Figure 2 - Estimate of the ruminal ammonia concentrations on the collection times $(T)$, for each concentrate level in the diet.

a resposta contrária foi possivelmente em virtude do aumento nas concentrações de PB das rações, relatado por TIBO et al. (2000). Comportamento semelhante para as variações nas concentrações de N$\mathrm{NH}_{3}$ no fluido ruminal foi obtido por VALADARES et al. (1997b), que forneceram dietas com níveis de PB que variaram de 7,0 a $14,5 \%$ a bovinos, e por DIAS (1999), trabalhando com novilhos alimentados com os mesmos níveis de concentrado na dieta que os 
utilizados no presente trabalho.

As concentrações de $\mathrm{N}-\mathrm{NH}_{3}$ foram influenciadas quadraticamente pelos tempos de coleta, sendo máximas 3,6 horas após o fornecimento das rações, independente dos níveis de concentrados.

As concentrações máximas estimadas, de 15,17; 18,$52 ; 21,87 ; 25,22 ; \mathrm{e} 28,57 \mathrm{mg} / 100 \mathrm{~mL}$, para as rações com 25,$0 ; 37,5 ; 50,0 ; 62,5 ;$ e 75,0\% de concentrado, respectivamente, foram semelhantes às relatadas por LADEIRA (1998), para os mesmos níveis de concentrado nas dietas. As concentrações de $\mathrm{N}-\mathrm{NH}_{3}$ observadas para os tratamentos nos diferentes tempos foram superiores aos valores mínimos de 3,3e 8,0 mg/ $100 \mathrm{~mL}$, sugeridos por HOOVER (1986) como necessários para adequados crescimento microbiano e digestão da MO no rúmen, respectivamente.

A Figura 3 mostra a relação da concentração de amônia no rúmen, em função dos teores de PB e NDT das rações. Observa-se que ocorreu aumento nas concentrações de amônia com o incremento do teor de $\mathrm{PB}$, mas, à medida que se elevou o teor de NDT, houve pequena redução, que não foi significativa.

As rações com 25,0; 37,5; 50,0; 62,5; e 75,0\% de concentrado resultaram em taxas de passagem da digesta ruminal da ordem de 0,$052 ; 0,052 ; 0,055$; 0,055 ; e $0,042 . \mathrm{h}^{-1}$, respectivamente. DIAS (1999) observou valores de taxas de passagem de 0,065; 0,$081 ; 0,064 ; 0,049$; e $0,046 . \mathrm{h}^{-1}$, que foram pouco superiores aos deste trabalho.

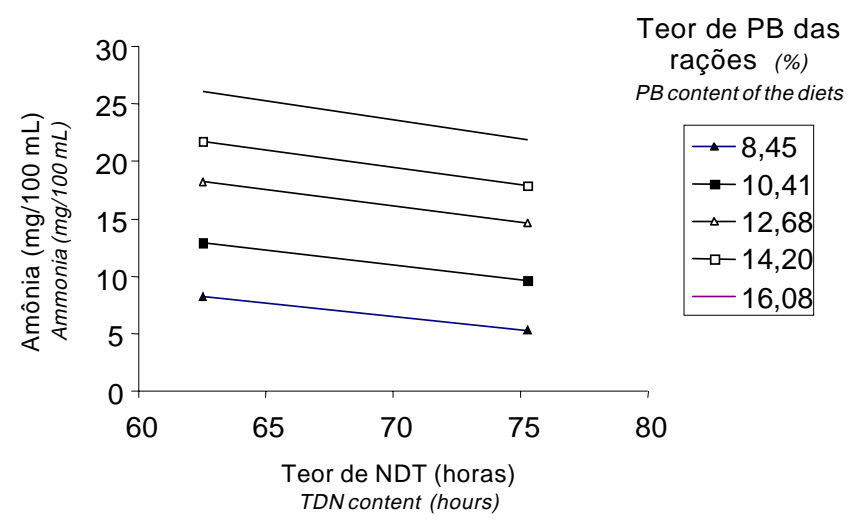

* Significativo a $5 \%$ de probabilidade pelo teste t. * Significant at $5 \%$ by $t$ test.

Figura 3 - Estimativa das concentrações da amônia ruminal, em função dos teores de proteína bruta (PB) e nutrientes digestíveis totais (NDT) das rações.

Figure 3 - Estimate of the ruminal ammonia concentrations on the dietary crude protein $(C P)$ and total digestible nutrients (TDN) contents.
CARVALHO et al. (1997) relataram taxa de passagem média de $0,035 . \mathrm{h}^{-1}$, quando adicionaram concentrado à dieta de zebuínos, atribuindo este comportamento ao elevado teor de fibra e à baixa qualidade do volumoso utilizado. BERCHIELLI (1994), testando dietas com feno de coast-cross e três níveis de concentrados (20, 40 e $80 \%)$, não constatou efeito da adição de concentrado, obtendo taxa de passagem média de $0,083 . \mathrm{h}^{-1}$.

A relação entre a taxa de passagem $(\mathrm{Kp} \%)$ e os níveis de concentrado foi avaliada por intermédio da seguinte equação de regressão: $\mathrm{Kp}(\%)=2,7999+$ $0,1212 \mathrm{C}-0,0013 \mathrm{C}^{2}\left(\mathrm{r}^{2}=0,74\right)$, em que Cé o nível de concentrado na ração em porcentagem. Por intermédio desta equação, a taxa de passagem estimada máxima de $0,056 \mathrm{~h}^{-1}$ foi obtida com $46 \%$ de concentrado na dieta. Vale ressaltar que os coeficientes linear e quadrático desta equação só seriam significativos em nível de 10,65 e 9,04\% de probabilidade, respectivamente.

\section{Conclusões}

As eficiências máximas de síntese microbiana de 41,22 Nmic/kg MODR, 39,89 g Nmic/kg CHODR e $17,33 \mathrm{~g} \mathrm{PBmic/100g}$ NDT foram estimadas com 52,2; 60,$4 ;$ e $56,6 \%$ de concentrado na dieta, respectivamente.

As concentrações de amônia no líquido ruminal cresceram linearmente com aumento nos níveis de concentrado; o valor máximo foi estimado às 3,60 horas após alimentação, independente do nível de concentrado.

A adição de concentrado nas rações proporcionou maior retenção de compostos nitrogenados no corpo do animal.

As perdas endógenas de NMF, equivalentes a $5,15 \mathrm{~g}$ de N/kgMS ingerida, e perdas endógenas totais de $422 \mathrm{mg}$ de $\mathrm{N} / \mathrm{kg}^{0,75}$ foram estimadas.

\section{Referências Bibliográficas}

AGRICULTURAL AND FOOD RESEARCH COUNCIL AFRC. 1993. Energy and protein requirements of ruminants. Wallingford, UK: CAB international. 159p.

AGRICULTURAL RESEARCH COUNCIL - ARC. 1984. Report of the protein group of the Agricultural Research Council working party on the nutrient requirements of ruminants. London: Commonwealth Agricultural Bureaux, 45p.

BERCHIELLI, T.T. Efeito da relação volumoso: concentrado sobre a partição da digestão, a síntese de proteína microbiana, produção de ácidos graxos voláteis e o desempenho de novilhos em confinamento. Belo Horizonte MG: UFMG, 1994.104p. Tese (Doutorado em Zootecnia) - Universidade 
Federal de Minas Gerais, 1994.

CARVALHO, A.U., VALADARES FILHO, S.C., COELHO DA SILVA, J.F. et al. 1997. Níveis de concentrados em dietas de zebuínos. 4. Concentrações ruminais de amônia e pH, taxa de passagem de digesta ruminal e degradação in situ dos alimentos. R. Bras. Zootec., 26(5):1016-1024.

CECAVA, M.J., MERCHEN, N.R., BERGER, L.L. et al. 1991. Effects of dietary energy level and protein source on nutrient digestion and ruminal nitrogen metabolism in steers. J. Anim. Sci., 69(8):2230-2243.

CECAVA, M.J., MERCHEN, N.R., GAY, L.C. et al. 1990. Composition of ruminal bacteria harvested from steers as influenced by dietary energy level, feeding frequency and isolation techniques. J. Dairy Sci., 73(9):2480-2488.

CHEN, X.B., GOMES, M.J. 1992. Estimation of microbial protein supply to sheep and cattle based on urinary excretion of purine derivatives - an overview of the technical details. Bucksburnd, Aberdeen: Rowett Research Institute. 21p. (Ocasional publication.)

CLARK, J.H., KLUSMEYER, T.H., CAMERON, M.R. 1992.Microbial protein synthesis and flows of nitrogen fractions to the duodenum of dairy cows. J. Dairy Sci., 75(8):2304-2323.

COELHO DA SILVA, J.F., LEÃO, M.I. 1979. Fundamentos de nutrição dos ruminantes. Piracicaba: Livroceres. 380p.

CZERKAWSKI, J.W. 1986. An introduction to rumen studies. Pergamon International Oxford: Library. p.31-44.

DIAS, H.L.C. Consumo, digestibilidade e eficiência microbiana em novilhos $F 1$ Limousin $x$ Nelore alimentados com dietas contendo cinco níveis de concentrado. Viçosa, MG: UFV, 1998. 76p. Dissertação (Mestrado em Zootecnia) - Universidade Federal de Viçosa, 1999.

HOOVER, W.H. 1986. Chemical factors involved in ruminal fiber digestion. J. Dairy Sci., 69(6): 2755-2766.

HOOVER, W.H., STOKES, S.R. 1991. Balancing carbohydrates and proteins for optimum rumen microbial yield. J. Dairy Sci., 74(8):3630-3644.

LADEIRA, M.M. Consumo e digestibilidades aparentes totais e parciais de dietas contendo diferentes níveis de concentrado, em novilhos nelore. Viçosa, MG: UFV, 1998. 71p. Dissertação (Mestrado em Zootecnia) - Universidade Federal de Viçosa, 1997.

NATIONAL RESEARCH COUNCIL - NRC. 1996. Nutrient requirements of beef cattle. 7.ed. Washington: National Academy. 242p.

NOLAN, J.V. 1993. Nitrogen kinetics. In: FORBES, J.M., FRANCE, J. (Eds.) Quantitative aspects of ruminant digestion and metabolism. Wallingford: Cambridge University Press. p.123-144.

RUSSELL, J.B. 1992. Minimizing ruminant nitrogen losses. In: SIMPÓSIO INTERNACIONAL EM RUMINANTES, Lavras, 1992. Anais... Lavras: ESAL, p.47-64, 1992.
RUSSELL, J.B., O'CONNOR, J.D., FOX, D.J. et al. 1992. A net carbohydrate and protein system for evaluating cattle diets: I ruminal fermentation. J. Anim. Sci., 70(11):3551-3561.

SILVA, D.J. 1990. Análise de alimentos (métodos químicos e biológicos). Viçosa, MG: UFV, Impr. Univ. 165p.

SNIFFEN, C.J., ROBINSON, H. 1987. Microbial growth and flow as influenced by dietary manipulations. J. Dairy Sci., 70(3):425-441.

STERN, M.D., HOOVER, W.H. 1979. Methods for determining and factors affecting rumen microbial protein synthesis: a review. J. Anim. Sci., 49(5):1590-1603.

TIBO, G.C., VALADARES FILHO, S.C., COELHO DA SILVA, J.F. et al. 2000. Níveis de concentrado em dietas de novilhos F1 Simental x Nelore: 1- Consumo e digestibilidades. Rev. bras. zootec., 29(5):921-929.

USHIDA, K., LASSALAS, B., JONANY, J.P. 1985. Determination of assay parameters for RNA analysis and duodenal samples by spectrophotometry. Influence of sample treatment and preservation. Reprod. Nutr. Develop., 25(6): 1037-1046.

VALADARES FILHO, S.C. Eficiência de síntese de proteína microbiana, degradação ruminal e digestibilidade intestinal da proteína bruta, em bovinos. In: SIMPÓSIO INTERNACIONAL SOBRE EXIGÊNCIAS NUTRICIONAIS DE RUMINANTES, 1995, Viçosa. Anais... Viçosa, MG: DZO, 1995. p.355-388.

VALADARES, R.F.D., GONÇALVES, L.C., SAMPAIO, I.B.M. et al. 1997a. Níveis de proteína em dietas de bovinos. 2. Consumos, digestibilidades e balanços de compostos nitrogenados. R. Bras. Zootec., 26(6):1259-1263.

VALADARES, R.F.D., GONÇALVES, L.C., SAMPAIO, I.B.M. et al. 1997b. Níveis de proteína em dietas de bovinos. 3. pH, amônia e eficiência microbiana. R. Bras. Zootec., 26(6):1264-1269.

VAN SOEST, J. 1994. Nutritional ecology of the ruminant. Cornell University Press, Ithaca. 476p.

VIEIRA, F. Efeito do formaldeído na proteção de proteínas e lipídios em rações para ruminantes. Viçosa, MG: UFV, 1980. 98p. Tese (Doutorado em Zootecnia) - Universidade Federal de Viçosa, 1980.

ZINN, R.A., OWENS, F.N. 1983. Influence of feed intake level on site of digestion in steers fed a high concentrate diet. $J$. Anim. Sci., 56(3):471-475.

Recebido em: 12/04/99

Aceito em: 13/10/99 